\title{
EIT MUSEOLOGISK PERSPEKTIV
}

\author{
John Aage Gjestrum
}

Innanfor det som er mogleg på nokre ganske få sider, skal eg dra opp eit perspektiv på disiplinen museologi, eit fag som ennå ikkje har fätt fotfeste i norsk universitets- eller museumsroyndom. Dette trass $i$ at museumsorganisasjonar, statlege organ og alle universiteta $i$ landet gjennom dei tre siste tiåra har hatt store utreiingsarbeid på området, og gjort forsøk på å få aktivitetar igang. Eit spørsmål som kan reissast, er derfor kvifor dei faktiske resultata er så magre når kravet om utdanningstilbod på feltet har vore eintydig?

Internasjonalt representerer feltet eit sterkt veksande fagområde, og dei siste 6-7 åra har på mange måtar vist ei nyorientering i forskinga med ei aukande mengd av publisert arbeid. Samstundes synest museer og kulturarv å bli stadig viktigare som kulturelle markørar i vår tid. Ei utvida forståing av museumsfenomenet innebær og viktig auke i vår kunnskap om det moderne menneske og kultur i det heile.

I Norge har det gjennom dei siste 30 åra frå mange hald vore uttrykt ønske og gjort faktiske forsøk på å få etablert museologi som fagdisiplin. I ettertid kan resultata frå desse 30 åra oppsummerast som nærast eintydig negative.

På 1960-talet vart det tatt initiativ i museumsorganisasjonane. Innstillinga Et norsk museumsseminar låg føre i 1965. På 1970-talet kom universiteta til: I 1972 vart det reist forslag om å opprette museologi som fag i Bergen (Kloster 1972), - i 1973 vart det arrangert fagkurs i museologi ved Vitskapsmu- seet og Universitetet i Trondheim. Men etter tre år stoppa det opp. Dei regionale høgskulane i Stavanger og Bø i Telemark la frà siste halvdel på 1970-talet inn visse museumsretta deler i kulturarbeidarutdanninga. I 1985-86 var det framme forslag om å etablere grunnfag i museumskunnskap ved Universitetet i Tromsø. Frå 1987 blir det kvart år gitt tilbod om ei halvårseining i museumskunnskap ved Universitetet i Oslo.

Museumsorganisasjonane og etter kvart Statens Museumsråd (i funksjon 1979-1991) arbeidde med museumsutdanning gjennom nye utgreiingar, komitear og konferansar gjennom heile 1970- og 80-talet (Gjestrum 1988).

Dette står i skarp kontrast til det som skjedde da museumsforbundet vart oppretta i 1918. Da tok ein opp "Kravet til norske museumsmænds faglige utdannelse" som eit av fire hovudoppgåver i arbeidsprogrammet. Museumsforbundet hadde forslaget klart til løysing, - det var å få til obligatorisk undervising i norsk kunsthistorie og arkeologi ved 
54 universitetet (den gong berre universitet i Kristiania) "saaledes at der for dem som vil gaa museumsveien maa bli adgang til å ta examen i faget ved Universitetet" (Gjestrum 1993). Frå kravet vart reist og til det heile var i orden gjekk det tre år. Frå 1921 var det høve til å ta magistergraden i arkeologi og kunsthistorie. Seinare kom etnologi til i 1941.

På 1960-talet var det imedlertid klart at ein i museumsarbeid trong noko meir enn spesialiserte gjenstandsfag. Kloster-komitéen som i 1972 la fram forslag om etablering av museologi ved Universitetet i Bergen peika på at det er "meget betenkelig at det ved ansettelse i museumsstillinger ikke stilles formelle krav til innsikt i museumsarbeidets teoretiske og praktiske grunnlag" (s. 20).

Kloster-komitéen la vekt på studiar av kva som skjedde i flere andre land, både i forståinga av kva museologi kunne vere og korleis musea vart aktiviserte.

Museene spiller en rolle i samfunnet, de integreres i undervisning og i forskning, de har sosiale oppgaver og de nyttes som medier. Deres register er blitt større og dette har igjen ført til at deres prinsipper og teori, museologien, har etablert seg som en nødvendighet $\mathrm{i}$ det museale arbeidet.

Museologien er den teoretiske, filosofiske bakgrunn for museumsarbeidet. Den låner elementer fra en rekke eksisterende fag og anvender disse innen museernes spesielle situasjon.

Museet er den integrerende part i faget museologi. Det består av mange "museologiske fag" som hver har sin metodikk korresponderende til den metodikk faget ville hatt som selvstendig vitenskapsgren (s. 21).

Innstillinga frå Kloster-komitéen føyer seg inn i den lange rekka med dokument som ikkje gav resultat. Når ein i ettertid ser attende på desse 30 åra, er det verkeleg skremmande at så mange framståande fagfolk innan muse- um, universitet og kulturområda har lagt fram så mykje vilje og meiningar og oppnådd så lite. Utan tvil ligg det ei interessant og utfordrande oppgåve i å granske korleis dette i det heile har vore mogleg.

Sidan noko slikt forskingsprosjekt ennå ikkje er gjort, kan eg heller ikkje gje fullgode og uttømmande svar på kvifor det har gått så gale. Noko vil eg likevel trekke fram som moment i moglege hypotesar:

- Ein har i alle desse åra ikkje greidd å skilje kva som skulle vere del i ei akademisk basisutdanning for museumsfeltet, og kva som skulle vere museas ansvat for fagleg oppdatering av sine eigne tilsette.

- Samstundes som ein har argumentert for musea som vitskaplege institusjonar knytta til dei ulike gjenstandsbaserte kultur-, kunst- og naturhistoriske vitskapane, har det heilt mangla vilje til å sjå vitskapleg (må forståast som = kritisk/analytisk) på museet som kulturelt/sosialt fenomen.

- Når det vitskaplege i musea så åleine er knytt til dei ulike gjenstandsvitskapane, vil det ved dei større musea - t.d. universitetsmusea - vere større integrering mellom arbeidet til den einskilde vitenskaplege medarbeider ved museet og fagfeller utanfor museet innan same fagområde, enn det vil vere mellom forskarar innanfor same museumsinstitusjon. Museet har ikkje noka eigen vitskapleg plattform å legge til grunn for tverrfagleg integrering.

- Dei viktige og gjennomgripande omskifta innan vitskapsteoretiske paradigme som har skjedd dei siste vel 30 åra har berre i liten grad nådd musea. Gamle positivistiske tenkjemåtar om objektiv, akkumulerande kunnskapsproduksjon lever trygt vidare.

- Museologi som eit vitskapleg og kritisk perspektiv på museumsfenomenet - påa alt frå 
korleis kultur- og naturarven blir konstruert ved urvalsprosessane - musealisering-, til kva bodskap og ideologi ein lar samlingane formidle, - fins altså knapt i Norge i dag. Derfor finst det ikkje verken nokon konsensus mellom fagfolk, eller nokon reell diskurs omkring kva ein er fagleg sams om eller ikkje sams om.

- Når ein undrast over kvifor situasjonen viser seg å bli fastlåst over så lang tid, må dette og ha noko å gjere med korleis vitskapssamfunnet fungerer. Utanfor musea, som ved universiteta, er ein i stand til å gjere store omskifte på relativt kort tid, t.d. ved val av fagprofil gjennom tilsettingar i vitskaplege stillingar, undervisingsformer, utforming av fagplanar og val av pensumslitteratur. Ein har heile tida brukarane - det vil seie studentane - i institusjonen som ei aktiv, kritisk og påverkande - til og med inspirerande - kraft.

I musea kan fagleg profilering og linjeskifte vere mykje tyngre å påverke. Tradisjonen er ikkje slik at skifte i fagstillingar inneber at dei som blir tilsette ser det som si oppgåve å gjennomføre endringer. Samlingane som alt er der, får legge premissane. Større endringar i utstillingar kan ligge langt utanfor det økonomisk realiserbare. Frå brukarane - publikum, som gjerne er ganske anonyme - kjem det oftast høflege, men ikkje særleg konstruktive tilbakemeldingar.

\section{IKKJE SPØRSMÅL, MEN FERDIGE SVAR?}

I 1985-86 la ein ved Universitetet i Tromsø fram ein plan som omfatta grunnfag i "museumskunnskap (museologi)". Studieplanskissa er eit typisk eksempel på ein "teknisk" og forvaltingsorientert tenkjemåte omkring museumsfeltet. Studiet var bygd opp i fem deler:
1. Ideologi, organisasjon og administrasjon

2. Innsamling, dokumentasjon og forskning

3. Oppbevaring, konservering og restaurering av museumsmateriale

4. Formidling/udadrettet virksomhet

5. Forvaltningsvirksomhet

(Kunst- og kulturfag ved Universitetet i Tromsø. 1986)

Det kanskje mest karakteristiske ved dette opplegget er oppfatninga av museumskunnskap som eit ferdig utvikla kunnskapsområde som så berre skal innlærast av studentane. Museumskunnskap slik ein legg det fram her inneheld ikkje åpne spørsmål, men ferdige svar. Det er ei reiskapsfag som skal gjere studenten eigna til å nytte sit "egentlige fag" (Hohler 1993) - kunsthistorie, arkeologi, etnologi, zoologi osb. i museet, - dei faga musea etter mange si meining er til for.

Halvårseininga i museumskunnskap som omlag 12 studentar får høve til å ta ein gong i året ved Universitetet i Oslo sedan 1987 er bygd opp på same måten. Museologisk teori som kritisk vitskap har liten plass i desse samanhengane.

\section{MUseologien FÅR EIT INNHALD}

Sjølv om vi altså har peika på ei lang historie med lite resultat, er det slik at dette òg gir føremoner idag.

Hadde det vore satsa mykje ressursar på undervisning i museologi på 1970-talet eller tidlig på 1980-talet, er det ikkje sikkert ein hadde hatt så mykje fagleg spennande innhald å legge inn.

I dei nordiske landa har enno ingen doktorert i museologi. I England skjedde det første gong i 1983 (Teather). Arbeidet med museologi i ICOM tog først fart på 1980-talet. Den internasjonale komitéen for museologi 
56 ICOFOM, tok frå 1983 til å publisere Icofom Study Series, som til nå er utgitt i vel 20 band.

Frå slutten av 1980-talet og først på 1990talet er det òg blitt ein ganske annleis storleik på det internasjonale fagmiljøet - noko som igjen kan avlesast gjennom talet på nye bøker og andre publikasjonar innan emnet.

Frå 1960-talet hugsar vi Germain Bazins bok "The Museum Age" (1967), frå 1970-talet nokre fleire: Alma S. Wittlin: "Museums: In Search of a Usable Future" (1970) og Kenneth Hudsons to bøker: "A Social History of Museums"(1975) og "Museums for the 1980s" (1977).

Litteraturen som kjem frå omkring midten av 1980-talet og framover avspeglar først og fremst ei langt breiare akademisk interesse for museumsfeltet, og nye vitskapsteoretiske perspektiv kjem inn. $\AA$ fange inn omfanget av denne litteraturen vil føre for langt her. Noko kan likevel trekkast fram:

Viktige teoretiske bidrag finn vi t.d. i Hobsbawms "The Invention of Tradition"(1983), i Hewison (1987) som formar omgrepet heritage industry, og i Pomian (1990) si påpeiking av at museas viktigaste funksjon er $a ̊ g j e r e ~ d e t$ usynlige synleg.

Susan Pearce leiar avdelinga Department of Museum Studies ved Universitetet i Leicester, England. Ei av dei mest interessante karakteristika ved musea ho trakk fram i den viktige boka "Museums, Objects and Collections" (1992) var at store delar av museumssamlingane var etablert som samlingar alt før gjenstandane kom til museum.

Desse spørsmåla er viktige når ein skal skjøne kva musea og musealisering som fenomen er for noko.

\section{Kulturarv， NaturarV， MilJøarV}

Per-Uno Ågren (1993) bruker nemninga miljöarven om den materielle kulturarven. Kulturarven inkluderer og naturarven ettersom seleksjon, klassifikasjon og forståing av naturen og skjer i kulturelle prosessar og institusjonar, mellom anna i museum.

Svante Beckman (1993) har vist korleis kulturarven kan forståast som ein infrastruktur i samfunnet, på line med andre infrastrukturar. Tilfeldig historisitet og konstruerte myter fungerer gjerne like godt som autentiske kulturarvelement. Ei spenning finst òg mellom ein holistisk kulturarv - slik som t.d. ulike sosiale og etniske grupper vil sjå på sin kulturarv - og på ein partikularisert kulturarv, - slik den finst i museumssamlinger og ofte blir forstått av profesjonelle aktørar i kulturvernområdet.

Einskilde kulturarvelement frå denne partikulariserte kulturarven vil så og kunne nyttest som sosiale markørar og til nostalgiproduksjon. Geir Vestheim (1994) viser korleis teoriane til den franske kultursosiologen Pierre Bourdieu om sosiale felt er fruktbare når ein analyserer museas funksjon.

Den kanadiske museumsmannen Duncan F. Cameron (1992) seier at skal vi forstå museumsinstitusjonane må vi forstå korleis dei har starta.

Too often we believe we know the origins of our institutions when what we have come to know are the myths and legends of convenience that masquerade as hallowed traditions.

Ut frå teoriane til Pearce og Cameron skal ein ikkje granske museas historie særleg lenge før det vert ganske klart at det ikkje er gjenstandsvitskapane som har skapt musea. I staden er det kan hende omvendt? 
Norske MUSEUM

\section{HAR OG EI HISTORIE}

Eit museumshistorisk riss viser at dei nåverande museumssamlingane i Norden vart etablert som kongelige samlinger på 1600-tallet; - for å kaste glans over kongehuset og gje det tilgang til datidas kunnskap utfrå gjeldande paradigmer. For Norge innebar dette at museumsaktiviteten skjedde utafor grensene, ved det danske kongehuset, hovudsakleg i København, der det kongelege kunstkabinettet frå ikring 1650 hadde ei fast organisering.

Opplysingstida og dei nye moderne perspektiva på vitskap og samfunn som følgde revolusjonstida frå slutten av 1700-tallet gjorde slutt på mykje av kongemaktas dominans og dermed også meininga med dei kongelege samlingane. Men gjenstandssamlingane levde vidare. I København fekk ein Nationalmuseet (namnet kom i 1855), grunnlagt i 1807 med ei lita oldsakssamling. Christian Jürgensen Thomsen (1788-1865) tok over leiinga frå 1817 og vart ein leiiande museumsmand i si tid for heile Norden.

Brotet mellom Danmark og Norge i 1814 kutta Norge av frå representasjonen av Norges historie som var bygd opp i Danmark gjennom 200 år.

Den nye unionsparten etter 1814, Sverige med Carl Johan i spissen, tok ikkje på seg oppgåva med ei kulturell integrering av Norge på samme måte som danskane hadde gjort. Dessutan innebar grunnlova frå 1814 som nordmennene hade fått igjennom, føresetnader om sjølvstende og suverenitet gjennom demokratiske institusjonar på ein måte som hittil ikkje var kjend i Norden.

Nå kjem eg til eit viktig poeng i den historiske utgreiinga: Det er i spenninga som oppstod etter etableringa av grunnlova og dei fyrste 10 krevande åra i unionstida med Sverige, at vi i Bergen fekk Norges fyrste eigenlege museum, Bergens Museum, som då vart etablert nettopp av ein av 1814-heltane, W.C. Christie.

Christie stod på sjølstendelina i 1814, men ikkje sterkare enn at han kunne ta del i etableringa av dei pragmatiske løysingane som måtte til hausten 1814 for å få til ei ordning med Sverige og Carl Johan. Samstundes hadde han i tida etterpå vore aktiv $\mathrm{i}$ å sikre grunnloven i maktkampen som gjekk føre seg mellom det nye norske folkestyret og den store uviljen svenskekongen hadde mot dette. To gonger avslo Christie tilbod frå Carl Johan om å bli statsråd. I kraft av sin kompetanse som jurist var Christie leiar for eit arbeid som gjennom juridiske grep skulle gje ei avklaring av tilhøvet mellom Norge og svenskekongen. Dette lukkast ikkje, og utover på 1820-tallet var det fleire svært spente situasjoner mellom Carl Johan og Norge.

Sjukdom gjorde at Christie i 1824 valde å søkje avskjed som stiftsamtmann. Han var berre midt i 40-åra, og stod nå utan dei pliktane ei sentral embetsstilling innebar. Etter ei lengre kurbadreise og opphald i sentrale tyske byer og København, utforma han framlegget sitt til etablering av Bergens Museum.

Det er viktig å merke seg at dette ikkje skjer som ei terapeutisk hobbyverksemd for eit aktivt samfunnsmenneske som nå var sett ut av spel. Nei, Christies initiativ og oppbygging av Bergens Museum må sjåast som ei strategisk handling sentralt plassert i datidas hovedspørsmål. Med grunnloven i 1814 hadde Eidsvollsrepresentantane greidd å legge eit grunnlag for eit faktisk folkestyre. Like mirakuløst hadde ein dei neste 5-6 åra greidd å stable nasjonaløkonomin på beina. Der dei juridiska grepa ikkje greidde å sikre framtida til den 
58 nye fridomen, kunne altså kultur, historie og vitskap gjere det.

Christie fant det derfor "gavnligt at tænke paa en Forening imellem oplyste, for Videnskaberne og Konsterne i Almindelighed og for Historien i Særdeleshed nidkjære, samt for Norges Ære og Nationalitet omhyggelige Mænd" som skal skaffe fram ei offentleg samling i Bergen:

ei Museum for Oldsager og Konstsager, og et Naturaliekabinet af indenlandske Naturalier...Nytten av en saadan Samling lader sig ikke forud i det Hele beregne; men høist sandsynligt er det, at Samlingen vil kunne tjene til at utbrede Lys i den norske Historie, og at redde fra Undergang Minder om Fortiden; at lære nøiere at kjende en eller anden av de Skatte, som Klipperne, Jorden eller Havet indeslutte, og at give Anledning til, at Landets Indbyggere høste Fordele deraf.

(Frå opprop 1825)

Om planen til Christie var ambisiøs, og realiseringen kan hende vart meir krevande enn han fyrst hadde tenkt, fekk museumslaget stor oppslutning. Allereie i 1831 kunne Bergens Museum kjøpe sin eigen bygning til samlingane. Og i 1840 flytta dei inn i det fyrste museumsbygg nokon gong bygd i Norge.

Og like viktig: Bergens Museum vart snart ein modell for museum i så å seia alle viktige byar i landet: Kristiansand prøvde å etablere museum 1828, men lukkast ikkje. Vidare kom: Arendal 1832, Ålesund 1866, Tromsø 1872, Trondheim 1874, Stavanger 1877 , Skien 1891, Tønsberg 1894 og Kristiansund 1894.

På 50-årsdagen for grunnloven i 1814 vart grunnsteinen for det nåvarande museumsbygget til Bergens Museum lagt ned 17. mai 1864. I hovudstaden Kristiania var det fleire mindre samlinger av oldsaker, mynter og anna. Dei vart etterkvart knytta til universi- tetet som var etablert i 1811. Men det var fyrst i 1828-29 dei vart permanent offentleg tilgjengelege (Universitetets oldsakssamling). Nationalmuseet (frå 1851 med namnet Nasjonalgalleriet) vart åpna på slottet i 1842, men fekk ikkje noko eige hus før mot slutten av hundreåret.

På 1800-talet var museum eit byfenomen, knytta til vide altomfattande samlingar og eit opplyst borgerskap. Friluftsmuseum og oppfatninga av norske museum som knytta til bondekultur og nasjonal byggjeskikk er noko som stort sett høyrer 1900-talet til. Det ligg da og venter mange spennande forskingsoppgåver i museumshistoria frå 1800-talet.

\section{EPILOG}

Kva skjedde så med museet Christie etter 15 år med hardt arbeid greidde å få bygd i 1840, og som var det aller fyrste museum bygd $\mathrm{i}$ Norge? Etter det kom nytt museumsbygg i 1860-åra, var det mellom anna skole, og snart var det gløymt. Eg er faktisk ikkje sikker om nokon eigentleg var klar over kva slags monument dei reiv i Bergen omkr. 1970, da dei satte opp det nye rådhuset. Nabohuset til Christies museum, Manufakturhuset, vart redda frå riving, for det vart vurdert som antikvarisk verdfullt.

Kan det vere mogleg å tenkje seg at museologien kan gjere museumsfolk meir medvitne om at dei sjølve og musea faktisk på same vis som andre fenomen i samfunnet også eksisterer i ein historisk samanheng? At dei på same vis som forgjengarane står $\mathrm{i}$ ein nåtidig og aktuell samfunnssituasjon. Forståinga kvifor musea er blitt til og kva dei har vore, kan òg seie oss idag noko om kva museum kan vere for oss og for vår tid. 


\section{Note}

- Texten trycktes ursprungligen i Årbok for Bergens Museum 1995 (1996).

\section{LitTERATURLISTE}

Beckman, Svante (1993): Om kulturarvets väsen och värde. I: J. Anselm (red.) Modernisering och kulturarv. Stockholm/Stehag, s. 61-124.

Brunchorst, J. (1900): Bergens Museum 1825-1900. Bergen.

Cameron, Duncan Ferguson (1992): A Change of Heart. I: Museum, Management and Curatorship 11, s. 375-386.

Gjestrum, John Aage (1988): En norsk museumshøgskole. Utredning for NKKM 1988.

Gjestrum, John Aage (1994): Kommentar til Erla B. Hohler: Hva er Museologi? Myte eller Metode? I: Helliesen, Sidsel og Tønseth, Britta (red.): M for Museum. Rapport fra jubileumsseminar. Oslo 3.6. juni 1993. Oslo, s. 43-49.

Gjestrum, John Aage (1993): "Museumsmænd og deres skidne tøi". Museumsnytt 1993:2, s. 4-15.

Gjestrum, John Aage (1995): Museology and research - in a Norwegian perspective. Nordisk Museologi 1995:2, s. 5-22.

Hewison, Ralph (1987): The Heritage Industry. London.

Hobsbawm, Eric and Ranger, Terence (1983): The Invention of Tradition.

Kloster, Robert (1972, formann): Instilling fra komitéen til utredning av museenes stilling innen universitetsstrukturen. Bergen.

Pearce, Susan M. (1992): Museums, Objects and Collections: A cultural Study. Leicester and London.

Pomian, Krzysztof (1990): Collectors and Curiosities. Cambridge.

Shapiro, Michael Stephen (1990 red.): The Museum: A Reference Guide. New York, London, Westport.
Shetelig, Haakon (1944): Norske museers historie.

Oslo.

Stansfield, Geoffrey og Woodhead, Peter (1994): Key-guide to Information Sources in Museum Studies. London og New York, 2. ed.

Teather, J. Lynne (1983): Museology and its Traditions. The British Experience 1845-1945. Upublisert doktoravhandling, Leicester.

Universitetet i Tromsø (1986): Kunst-og kulturfag ved Universitetet $i$ Tromsø.

Westheim, Geir (1994): Museum i eit tidsskifte. Oslo.

Walsh, Kevin (1992): The representation of the past. Museums and heritage in the postmodern world. London og New York.

Ågren, Per-Uno (1993): Museologi och kulturarv. Nordisk Museologi 1993:1, s. 61-65. 